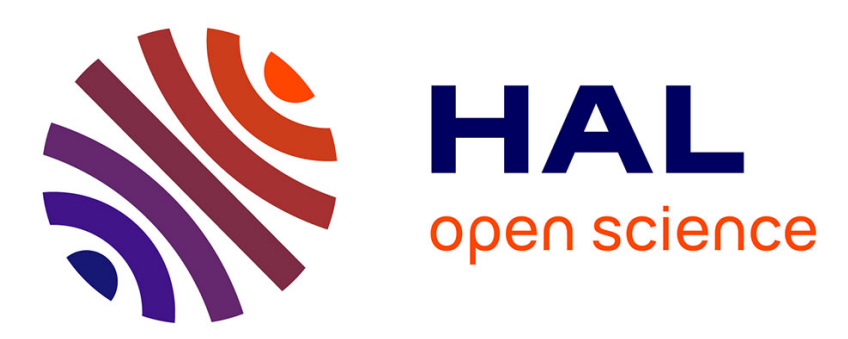

\title{
Terpyridine-Ru Complexes Noncovalently Supported on Cobalt Magnetic Nanoparticles for Nitroarene Transfer Hydrogenation
}

Houria Asri, Olivier Dautel, Armelle Ouali

\section{- To cite this version:}

Houria Asri, Olivier Dautel, Armelle Ouali. Terpyridine-Ru Complexes Noncovalently Supported on Cobalt Magnetic Nanoparticles for Nitroarene Transfer Hydrogenation. ACS Applied Nano Materials, 2020, 10.1021/acsanm.0c02337 . hal-03041332

\section{HAL Id: hal-03041332 \\ https://hal.science/hal-03041332}

Submitted on 14 Dec 2020

HAL is a multi-disciplinary open access archive for the deposit and dissemination of scientific research documents, whether they are published or not. The documents may come from teaching and research institutions in France or abroad, or from public or private research centers.
L'archive ouverte pluridisciplinaire HAL, est destinée au dépôt et à la diffusion de documents scientifiques de niveau recherche, publiés ou non, émanant des établissements d'enseignement et de recherche français ou étrangers, des laboratoires publics ou privés. 


\title{
Terpyridine-Ru Complexes Non-Covalently
}

\section{Supported on Cobalt Magnetic Nanoparticles for}

\section{Nitroarene Transfer Hydrogenation}

\author{
Houria Asri, Olivier Dautel, Armelle Ouali*
}

armelle.ouali@enscm.fr

Institut Charles Gerhardt Montpellier, UMR 5253 CNRS-UM-ENSCM. ENSCM, 8 rue de l'Ecole Normale, 34296 Montpellier Cedex 05, France

\section{KEYWORDS}

Magnetic nanoparticles (MNPs), $\pi$-stacking interactions, 2-propanol, Pyrene-tagged catalysts, nitroarene transfer hydrogenation.

\begin{abstract}
This work reports the preparation and characterization of active and recyclable supported catalysts involving molecular Ru-terpyridine complexes and able to promote the transfer hydrogenation of nitroarenes in 2-propanol. The system proposed is based on the design of original pyrene-tagged terpyridine ligands, either monomeric " 1 tpy" (one pyrene tag for one terpyridine) or multivalent "5tpy" (one pyrene tag for five terpyridines), able to interact with the graphene surface
\end{abstract}


of commercially available cobalt magnetic nanoparticles (MNPs) through $\pi$-stacking interactions. The existence of non-covalent interactions between the pyrene-tagged terpyridines and the MNPs surface at $20{ }^{\circ} \mathrm{C}$ was assessed by fluorescence spectroscopy for the first time in 2-propanol, an organic medium. Interestingly, $\mathbf{1}_{\text {tpy }}$ and $\mathbf{5}_{\text {tpy }}$ were shown to be released upon temperature increase $\left(80{ }^{\circ} \mathrm{C}\right)$ while the association was restored upon temperature decrease $\left(20^{\circ} \mathrm{C}\right)$. The reversibility of this phenomenon enabled to reach high activities in nitroarenes transfer hydrogenation for the corresponding $\mathrm{Ru}$ complexes (catalytic species are free in refluxing 2-propanol) and high recyclabilities (non-covalent interactions are restored upon cooling). Noteworthy, the multivalent ligand $\mathbf{5}_{\text {tpy }}$ displaying as expected the higher terpyridine loading $(0.15 \mathrm{mmol}$ of tpy / g of MNPs vs $0.03 \mathrm{mmol}$ for $\mathbf{1}_{\text {tpy }}$ ), also gave rise to the Ru-catalyst with the best recyclability ( 8 consecutive cycles with no loss of activity against 5 cycles for the catalyst based on monomeric ligand $\mathbf{1}_{\text {tpy }}$ ). In both cases, the ruthenium leaching was found to be low and the expected aniline met the requirements of the pharmaceutical industry $(<10 \mathrm{ppm} \mathrm{Ru})$ from the third run.

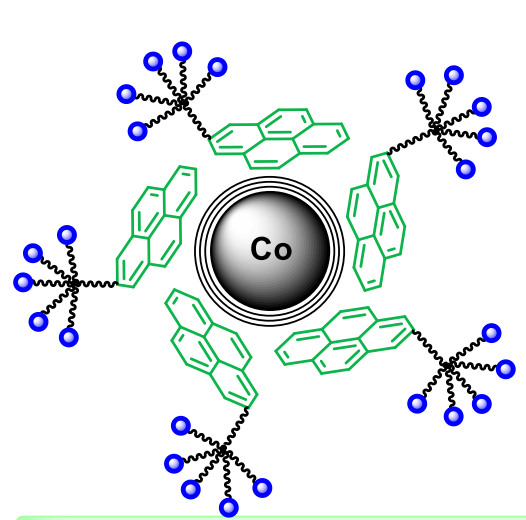

Catalyst [Ru] recovered at $20^{\circ} \mathrm{C}$
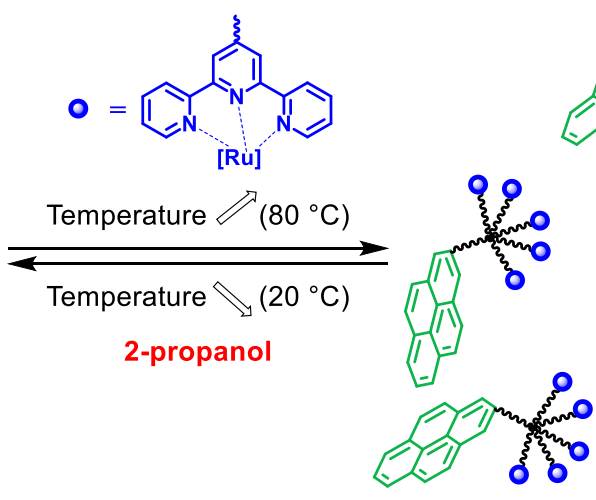

Reversibility of the $\pi-$ stacking interactions
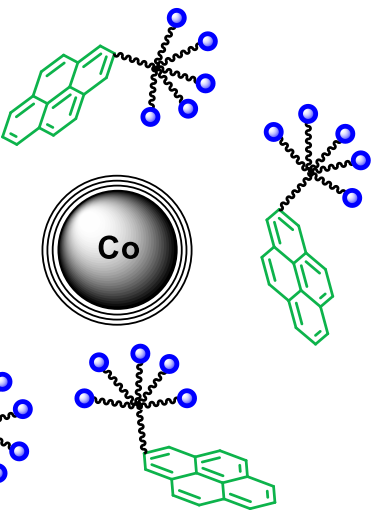

$[R u]$ free in the solution at $80^{\circ} \mathrm{C}$ (homogeneous conditions) 


\section{INTRODUCTION}

Heterogenization of homogeneous catalysts on supports including for e. g. polymers, silicas or magnetic nanoparticles has the potential to build bridges between homogeneous and heterogeneous catalyses. ${ }^{1}$ Expected advantages include the combination of the high catalytic activity inherent to the well-defined molecular catalyst and its easy separation from the reaction mixture with the possibility of reuse. However, some drawbacks have been highlighted including catalyst deactivation once immobilized and subsequent lower turnover numbers (as compared to corresponding homogeneous catalysts) as well as low recyclabilities. ${ }^{2}$ Besides, except in some rare cases, ${ }^{3}$ metal leaching cannot be avoided also leading to poor recycling ability and to the contamination of the products by metal traces. The design of supported catalysts combining high activities, high recyclabilities and low metal leaching thus still constitute a challenge. Among other supports, magnetic nanoparticles (MNPs) are particularly attractive for the development of more efficient and green processes. ${ }^{4}$ Indeed, their separation can easily be achieved by magnetic decantation with a simple magnet contrary to other supports, such as polymers or silica, which require time-consuming precipitation and filtration steps. Generally, MNPs are stabilized by coating the magnetic core with polymer or silica shells which are used for the covalent immobilization of homogeneous catalysts. ${ }^{4}$ First described by Stark and coll. $^{5}$ and now commercially available, ${ }^{6}$ graphene coated MNPs also enable the covalent immobilization of catalysts. ${ }^{5,7}$ In addition, they offer the unique possibility for non-covalent catalyst attachment by $\pi-\pi$ stacking and interestingly, the efficiency of these non-covalent interactions was found to

dependent on the temperature. ${ }^{8 \mathrm{a}-\mathrm{c}}$ Indeed, while the pyrene-tagged catalysts are associated to the MNPs at low temperature $\left(20-25^{\circ} \mathrm{C}\right)$, a dissociation was observed at higher temperatures $(>60$ $\left.{ }^{\circ} \mathrm{C}\right)$. Such behavior is reminiscent of catch-and-release systems for which the catalytic moiety is 
released in solution over the course of the reaction and is recaptured at the end thus enabling successful recovery. ${ }^{9}$ Reported "boomerang" systems involve different modes of recognition including hydrogen binding, ionic, host-guest or $\pi-\pi$ stacking interactions. ${ }^{9}$ Concerning the abovementioned Co/C MNPs, O. Reiser and coll. reported the non-covalent attachment of pyrene-tagged Pd-carbene complexes able to catalyze the hydrocarbonylation of aromatic halides in water ${ }^{8 a}$ Later on, some of us reported that the introduction of well-defined dendritic spacers between the pyrene tag and Pd-phosphine complexes (Figure 1) enabled to increase the loading of active palladium complexes active in Suzuki couplings. ${ }^{8 b}$ In both cases, the catalyst recovery was ensured in aqueous media (pure water ${ }^{8 \mathrm{a}}$ or water/THF $(5: 2)^{8 \mathrm{~b}}$ ) that favor efficient non-covalent interactions. ${ }^{8 \mathrm{~d}}$ One aim of this work was to design related systems enabling reversible interactions in organic media and in particular in 2-propanol, a cheap, benign and easy-to-handle $\mathrm{H}$ source employed in transfer hydrogenations of various substrates. ${ }^{10}$ Among the latter, nitroarenes give rise to anilines, key compounds finding widespread applications as intermediates and targets in pharmaceutical, agrochemical, pigments or dyes industries and holding a very high market share in organic chemistry industry. ${ }^{11}$ In general, the use of H-donors instead of molecular hydrogen for nitroarenes reduction enables to avoid high-pressure equipments. Besides, it is a more sustainable and benign methodology as compared to the historical stoichiometric Béchamp reduction involving metallic iron in acidic media generating a lot of wastes. A wide array of transition-metal based catalysts, mostly heterogeneous, promote nitroarenes transfer hydrogenations in the presence of different $\mathrm{H}$ sources such as formates, sodium borohydride or hydrazine. ${ }^{11 \mathrm{~b}}$ Although active in mild conditions and generally more tolerant in terms of functional groups, related homogeneous catalysts have been less studied. Whether homogeneous or heterogeneous, only a few catalysts are able to promote transfer hydrogenation using 2-propanol as the H-donor. ${ }^{11 b, 12}$ Along these lines, Beller 
and coll. reported a well-defined terpyridine-ruthenium complex catalyzing efficiently and selectively the reduction of a wide array of nitroarenes in 2-propanol under mild conditions. ${ }^{13}$ The reuse of ruthenium-based catalysts appears as highly desirable for economic and ecological reasons. Therefore, in this work, pyrene-tagged terpyridine-Ru complexes, either monomeric or multivalent, were prepared and associated to MNPs through $\pi$-stacking interactions for the first time in 2-propanol, an organic solvent. The activity and recyclability of both systems were evaluated in the transfer hydrogenation of nitrobenzene.

\section{EXPERIMENTAL SECTION}

\section{- Materials and methods}

THF was dried using mBRAUN purification system. All other solvents and chemical reagents were purchased from Sigma Aldrich, Acros or Alfa Aesar and used as received without further purification. Catalytic reactions were performed under nitrogen atmosphere using standard Schlenk technique. Nuclear Magnetic Resonance Spectroscopy (NMR) spectra were recorded with Bruker $400 \mathrm{MHz}$ device at room temperature in the indicated deuterated solvents. $\mathrm{All}{ }^{1} \mathrm{H},{ }^{13} \mathrm{C},{ }^{31} \mathrm{P}$ NMR spectra were evaluated in parts per million parties (ppm) and coupling constants (J) are reported in Hertz (Hz). The signals in the spectra are described as s (singlet), d (doublet), t (triplet), m (multiplet). Gas chromatography - mass spectra (GC-MS) were recorded on a ThermoFisher Scientific Trace GC Ultra instrument with a ThermoFisher Scientific ITQ 900 Ionic Trap and an Agilent DB-5MS $30 \mathrm{~m}$ x 0,25 mm capillary apolar column (Stationary phase: 0,25 $\mu \mathrm{m}$ film). Flash column chromatography was performed on silica gel (230-400 mesh) and analytical thin-layer chromatography (TLC) was carried out using $250 \mu \mathrm{m}$ commercial silica gel plates. MS spectra were obtained on a Synapt G2-S from Waters with a quadrupole cell collision. High resolution 
mass spectra (HRMS) were recorded on an Agilent 6210 ESI TOF (time of flight) mass spectrometer. UV-vis spectra and Fluorescence spectra were performed with a LS 55 Luminescence Spectrometer from Perkin Elmer. Solution characterizations were realized on diluted 2-propanol solutions. ICP-MS were performed on a Agilent 7900 apparatus.

- Fluorescence studies: Preparation of the solutions with concentrations $\sim 10^{-5} \mathrm{~mol}$. $\mathrm{L}^{-1}$ : For compound $\underline{\mathbf{3}}: 20 \mathrm{mg}$ of $\underline{\mathbf{3}}$ were dissolved in 2-propanol in a graduated flask of $100 \mathrm{~mL} .300 \mu \mathrm{l}$ of the stock solution were diluted in a graduated flask of $10 \mathrm{ml}$ (final concentration: $0.99 .10^{-5} \mathrm{~mol}^{-\mathrm{L}^{-}}$ ${ }^{1}$ ). For compound $\underline{\mathbf{5}}: 7 \mathrm{mg}$ of $\underline{\mathbf{5}}$ were dissolved in 2-propanol in a volumetric flask of $250 \mathrm{~mL}$ (final concentration of $\left.1.02 \cdot 10^{-5} \mathrm{~mol} . \mathrm{L}^{-1}\right)$.

Studies at $20^{\circ} \mathbf{C}$ (Figure 2): Solutions of pyrenes $\underline{\mathbf{3}}$ or $\underline{\mathbf{5}}$ in 2-propanol were prepared and their respective fluorescence spectra recorded. Aliquots of $\mathrm{Co} / \mathrm{C}$ MNPs were then successively added to these homogenous solutions ( $1 \mathrm{mg}$ for each addition). After each addition, the suspension was sonicated for $15 \mathrm{~min}$ at $20{ }^{\circ} \mathrm{C}$ in a closed tube (it was checked that no evaporation of the solvent occurred), the NMPs recovered by magnetic decantation and the supernatant analyzed by fluorescence spectroscopy.

Note: the addition of MNPs to solutions of $\underline{\mathbf{3}}$ and $\underline{\mathbf{5}}$ also induced a decrease of the absorption intensity by UV-vis spectroscopy (see Supporting Information, Figure S15). This confirms that the decrease of emission intensity mostly resulted from the decrease of the ligand concentration and not from other possible deactivation pathways (quenching, temperature, impurities...).

\section{Influence of the temperature on the $\pi$-stacking interactions efficiency (Figure 3):}

Solutions of pyrenes $\underline{\mathbf{3}}$ or $\underline{\mathbf{5}}$ in 2-propanol were prepared and their respective fluorescence spectra recorded (blue curves). MNPs were added (1 mg in the case of $\underline{\mathbf{3}} ; 0.4 \mathrm{mg}$ in the case of $\underline{\mathbf{5}}$ ) and the 
suspensions were sonicated for 15 minutes at $20{ }^{\circ} \mathrm{C}$ in closed tubes (fluorescence of the resulting supernatants: red curves). Then the supernatants and the MNPs were gathered and allowed to sonicate for $2.5 \mathrm{~h}$ at $80^{\circ} \mathrm{C}$ (still in closed tubes). After "hot magnetic decantation", fluorescence spectra of the supernatants were recorded (green curves). The latter were one more time associated to the previously recovered MNPs and the corresponding suspensions sonicated for $2 \mathrm{~h}$ at $20{ }^{\circ} \mathrm{C}$. The supernatants were analyzed by fluorescence spectroscopy (purple curves). Note: After each sonication steps, it was checked that no evaporation of the solvent occurred.

- General procedure for recycling experiments: In a Schlenk tube equipped with magnetic stirring bar, under nitrogen atmosphere, the catalyst was generated in situ from $\left[\left\{\mathrm{RuCl}_{2}(\mathrm{p}-\right.\right.$ cymene $)\}_{2}$ ] (12.0 $\left.\mathrm{mg}, 0.0125 \mathrm{mmol}\right)$ and ligand $(0.025 \mathrm{mmol}$ of terpyridine moieties: $0.025 \mathrm{mmol}$ $=15.2 \mathrm{mg}$ for $\underline{\mathbf{3}}, 0.005 \mathrm{mmol}=13.7 \mathrm{mg}$ for $\underline{\mathbf{5}})$ in 2-propanol $(5 \mathrm{ml})$ for $30 \mathrm{~min}$ at $60^{\circ} \mathrm{C}$. MNPs (500 $\mathrm{mg}$ for $\underline{\mathbf{3}}, 100 \mathrm{mg}$ for $\underline{\mathbf{5}}$ ) were introduced and the mixture sonicated for 30 minutes at $20^{\circ} \mathrm{C}$. The nitroarene $(0.5 \mathrm{mmol}), \mathrm{KOH}(0.075 \mathrm{mmol}, 4.2 \mathrm{mg})$, and 2-propanol $(5 \mathrm{ml})$ were next added. After 15 hours at reflux (temperature of the oil bath: $100^{\circ} \mathrm{C}$ ), the reaction mixture was cooled to room temperature, sonicated for 30 minutes at $20{ }^{\circ} \mathrm{C}$ and magnetic decantation was performed thanks to the magnet. The MNPs were rinsed twice with 2-propanol (1 mL). The standard 1,3,5trimethoxybenzene was added to the joined solutions and the mixture obtained analyzed by ${ }^{1} \mathrm{H}$ NMR (after evaporation of the solvent) and GC-MS. To the hybrid MNPs dried under vacuum, nitroarene $(0.5 \mathrm{mmol})$ chosen for the next run and 2-propanol $(10 \mathrm{~mL})$ were added and the same procedure was repeated at each run. 


\section{RESULTS AND DISCUSSION}

The first objective consisted in preparing terpyridine ligands bearing a pyrene tag able to interact with the graphene surface of the MNPs. Two systems were targeted: the first one involved a pyrene moiety connected to a terpyridine ligand through an organic linker (Figure 1a) and the second one consisted in a pyrene tag linked to five terpyridine ligands through a multivalent spacer (Figure 1b).

(a) Monomeric pyrene-tagged ligand

0 = terpyridine ligand
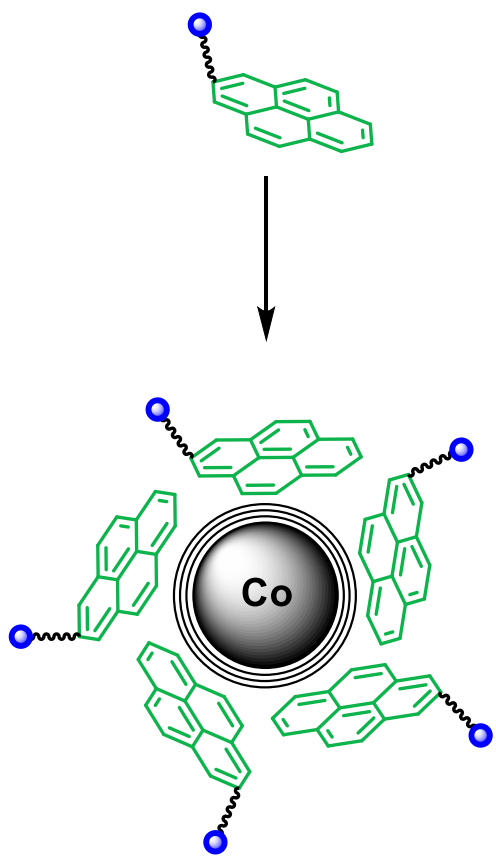

(b) Multivalent pyrene-tagged ligand:

$\Rightarrow$ towards enhanced ligand loading
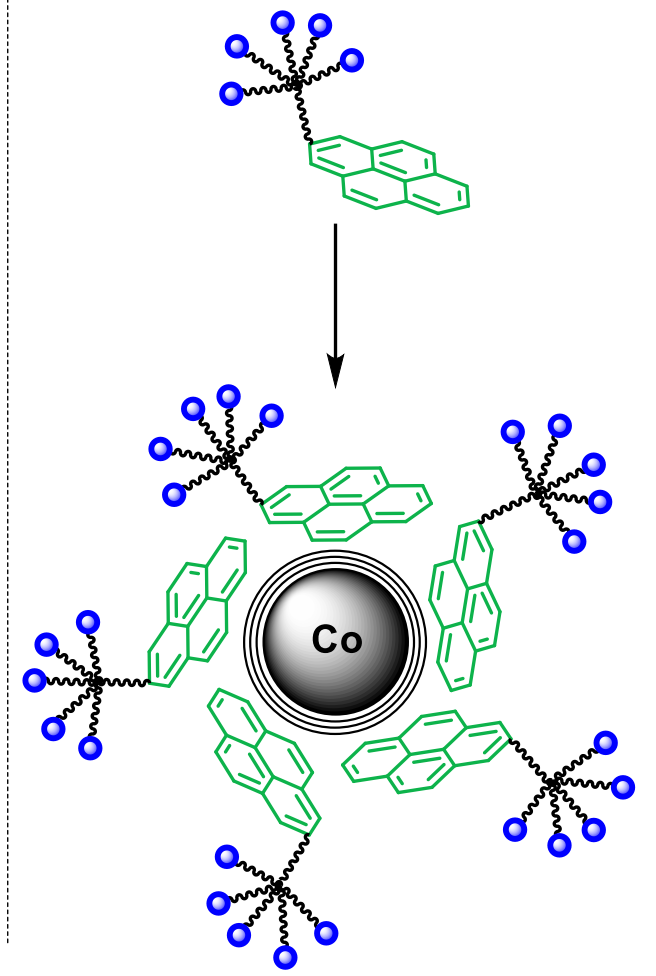

Figure 1: Targeted pyrene-tagged ligands involving either 1 (a) or 5 (b) terpyridine ligands and their corresponding expected hybrid MNPs

Concerning the synthesis (Scheme 1), the peptide coupling between commercial 1-pyrenebutyric acid and amine $\underline{\mathbf{2}}$ (described for the first time, prepared quantitatively in one step and fully characterized, see SI p. S2 and Fig. S3 to S5), yielded pyrene $\underline{\mathbf{3}}$ bearing one terpyridine moiety in $74 \%$ yield. The corresponding multivalent ligand $\underline{\mathbf{5}}$ bearing five terpyridines was obtained in $79 \%$ 
yield through reductive amination of previously described aldehyde-decorated dendron $\underline{4}^{8 \mathrm{~b}}$ with amine $\underline{\mathbf{2}}$. Both ligands were characterized by multi-nuclear RMN spectroscopy. The signals, that could be assigned, were consistent with the successful preparation of $\underline{\mathbf{3}}$ and $\underline{\mathbf{5}}$ (see SI p. S3-S5, Fig. S6-S7 and S9-S11). In addition, high resolution mass spectroscopy also confirmed the structures (see SI, Fig. S8 and S12). Noteworthy, several compounds associating one pyrene and one terpyridine were reported in the literature: both moieties can be covalently connected (directly ${ }^{14}$ or via an organic linker ${ }^{15}$ ) or linked in a non-covalent manner (for e. g. via coordination ${ }^{16}$ or other weak bonds in supramolecular assemblies ${ }^{17}$ ). Other compounds display non-equimolar pyrene-toterpyridine ratios such as structures with 3 pyrenes pods able to interact with graphene and one terpyridine-metal complex bringing optical properties. ${ }^{18}$ Conversely, tetra-substituted pyrenes were used as multifunctional cores bearing 2 or 4 terpyridines. ${ }^{19}$ The pyrene-tagged mono- and penta-terpyridines reported here clearly differ from the known related compounds. Indeed, compound $\underline{\mathbf{3}}$ includes an original covalent flexible linker and, for $\underline{\mathbf{5}}$, the multivalency is ensured by the cyclotriphosphazene $\left(\mathrm{N}_{3} \mathrm{P}_{3}\right)$ moiety thus enabling to maintain the pyrene tag unsubstituted for optimized interactions with the graphene surface.

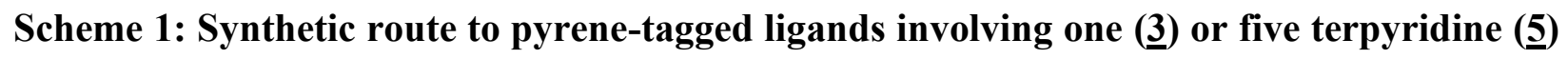
moieties.
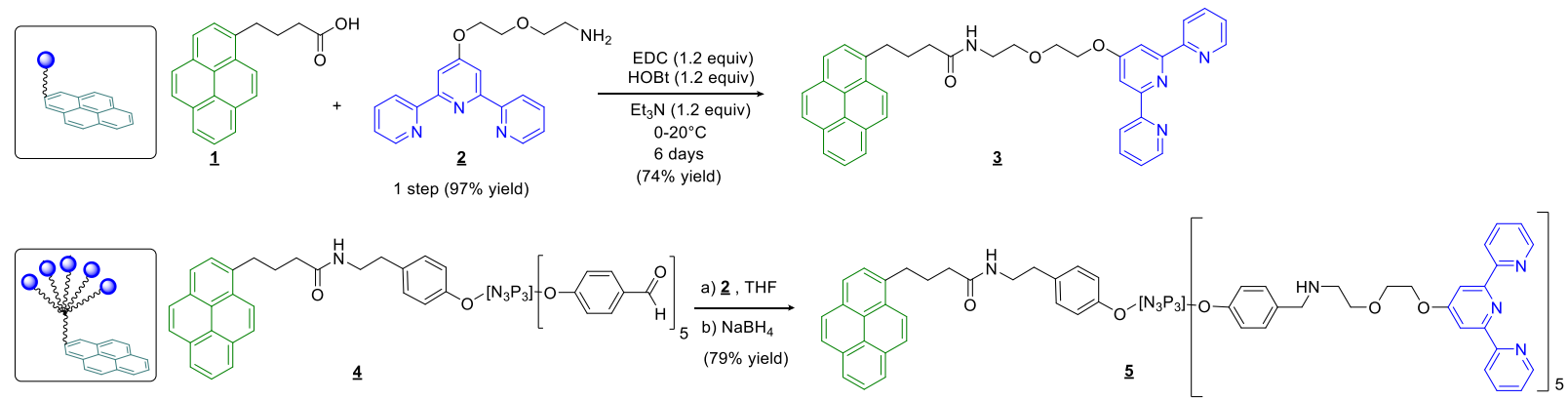

To assess the existence of interactions between the graphene surface and the pyrene moiety of $\underline{\mathbf{3}}$ and $\underline{\mathbf{5}}$, fluorescence studies were carried out. ${ }^{20} \mathrm{~A}$ preliminary UV-vis spectroscopy study allowed 
the determination of the wavelength of maximum absorbance $\left(\lambda_{\max }\right)$ for $\underline{\mathbf{3}}$ and $\underline{\mathbf{5}}$ ( $342 \mathrm{~nm}$ and 343 $\mathrm{nm}$, respectively, for solutions at $\sim 10^{-5} \mathrm{~mol} \mathrm{~L}^{-1}$ of each compound in 2-propanol (see SI, Fig. S13S14) in the absence of Co/C MNPs. Afterwards, the emission spectra of both compounds were recorded by irradiation at their respective $\lambda_{\max }$ (Figure 2, blue curve). The emission spectra of pyrene-tagged terpyridines $\underline{\mathbf{3}}$ and $\underline{\mathbf{5}}$ displayed two sharp bands and two broader bands in the range of 360-500 nm assigned to the pyrene monomer (Figure 2, a and b respectively, blue curves). Aliquots of Co/C MNPs (1 mg) were next successively added to these homogeneous solutions. After each addition, the suspension was sonicated for $15 \mathrm{~min}$, the MNPs removed by magnetic decantation and the supernatant analyzed by fluorescence spectroscopy. Each addition was found to induce an extinction of the emission intensity (Figure $2 \mathrm{a}, \mathrm{b}$ ) corresponding to a decrease of the concentration of pyrene-tagged $\underline{\mathbf{3}}$ or $\underline{\mathbf{5}}$ in the supernatant. These results supported the existence of interactions between the graphene surface of the MNPs and the pyrene-tagged ligands of $\underline{\mathbf{3}}$ and $\underline{\mathbf{5}}$. 
(a) Ligand $\underline{3}$

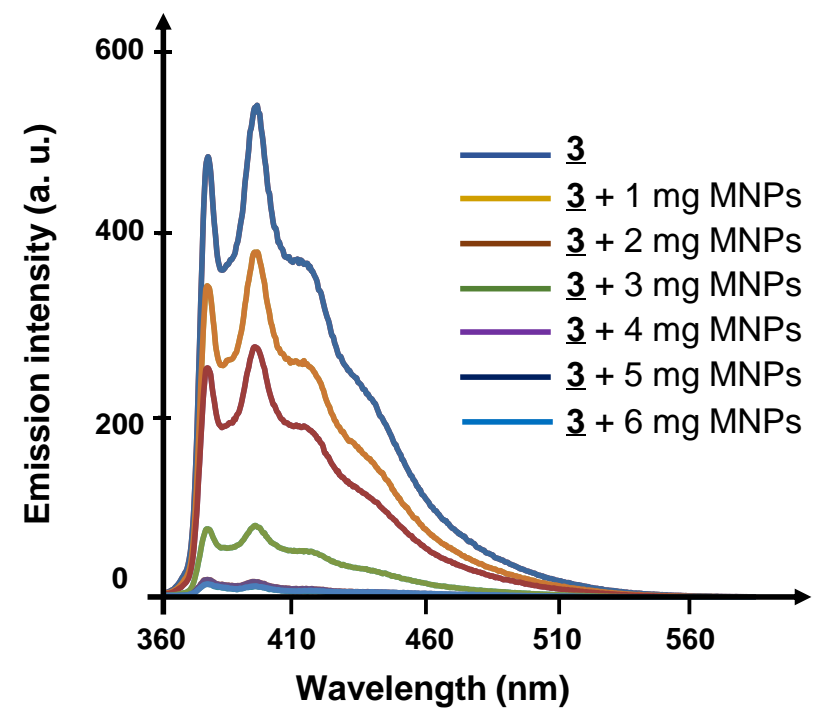

(b) Ligand $\underline{5}$

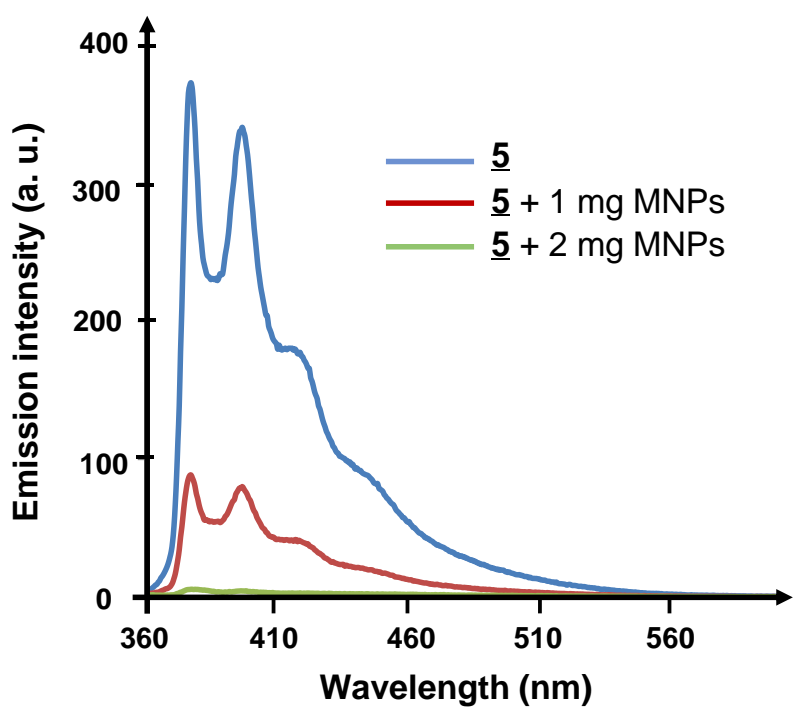

Figure 2: Fluorescence emission spectra of pyrenes $\underline{\mathbf{3}}$ (a) and $\underline{\mathbf{5}}$ (b) in 2-propanol at $20{ }^{\circ} \mathrm{C}$ in the absence of Co/C-MNPs $\left(10^{-5} \mathrm{~mol} \mathrm{~L}^{-1}\right.$, blue curve on the top). After each addition of MNPs, the suspension was sonicated for 15 minutes at $20{ }^{\circ} \mathrm{C}$, magnetically decanted and the emission spectra of the supernatant recorded and reported in these graphics (see details in Experimental Section).

Next, the influence of the temperature on the efficiency of the $\pi$-stacking interactions was studied. First and as before, the fluorescence emission spectra of $\underline{\mathbf{3}}$ or $\underline{\mathbf{5}}$ were recorded (Figure $\mathbf{3}$ a and $b$ respectively, blue curve). MNPs were then added and the mixtures sonicated for 15 minutes at $20{ }^{\circ} \mathrm{C}$, then decanted with a magnet and the fluorescence spectrum of the supernatant recorded (Figure 3, red curves). As expected according to previous experiments (Figure 2), the intensity was found to decrease in both cases (Figure 3 a and b respectively, red curves). 
(a) Ligand $\underline{3}$

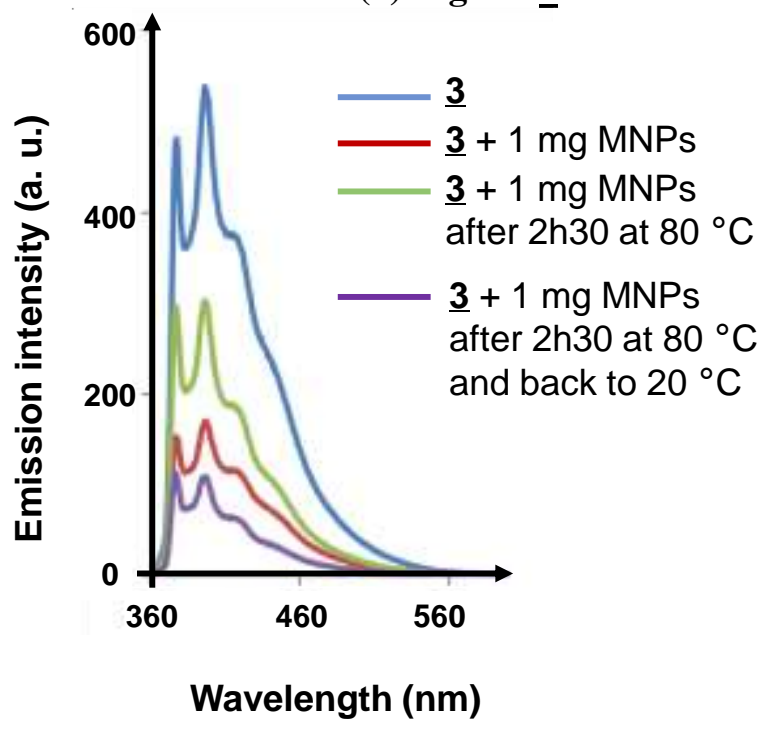

(b) Ligand $\underline{5}$

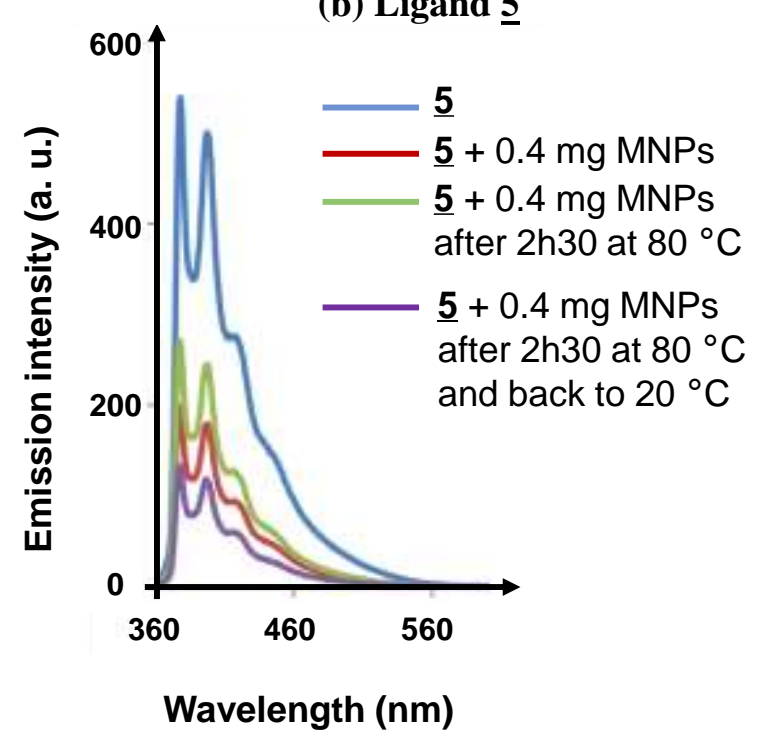

Figure 3: Reversibility experiments: a solution of $\underline{\mathbf{3}}$ (a) or $\underline{\mathbf{5}}$ (b) $\left(10^{-5} \mathrm{~mol} \mathrm{~L}^{-1}\right.$, blue curve for reference emission spectra) and MNPs was sonicated for 15 minutes at $20{ }^{\circ} \mathrm{C}$, magnetically decanted and the fluorescence spectrum of the supernatant recorded (red curve). The mixture (supernatant and MNPs) was then heated to $80{ }^{\circ} \mathrm{C}$ for $2.5 \mathrm{~h}$, and the spectrum of the resulting supernatant analyzed (green curve). Both the supernatant and the MNPs were next gathered and the mixture sonicated at $20{ }^{\circ} \mathrm{C}$ for $2 \mathrm{~h}$, the concentration of $\underline{\mathbf{3}}$ (a) or $\underline{\mathbf{5}}$ (b) in the solution decreased (purple curve) (see details in Experimental Section).

The supernatant and the MNPs were next gathered, the mixture heated up to $80{ }^{\circ} \mathrm{C}$ for $2.5 \mathrm{~h}$, and the spectrum of the resulting supernatant analyzed (Figure 3 a and b respectively, green curves). The latter experiment indicated that the concentration of pyrenes $\underline{\mathbf{3}}$ or $\underline{\mathbf{5}}$ increased in accordance with a partial release of $\underline{\mathbf{3}}$ and $\underline{\mathbf{5}}$ from the surface of the MNPs at $80{ }^{\circ} \mathrm{C}$. Upon cooling back to 20 ${ }^{\circ} \mathrm{C}$, the concentration of $\underline{\mathbf{3}}$ and $\underline{\mathbf{5}}$ in the solution decreased (Figure $\mathbf{3}$ a and b respectively, purple curves) suggesting the complete reversibility of the $\pi$-stacking interactions. The concentration of $\underline{\mathbf{3}}$ and $\underline{\mathbf{5}}$ in solution are lower for purple curves than for red ones which suggests that the equilibrium was not attained after 15 minutes at $20^{\circ} \mathrm{C}$ when recording red curves.

Next the hybrid MNPs were prepared according to the procedure described (see SI, Fig. S1). Solutions of pyrene-tagged terpyridines $\underline{\mathbf{3}}$ and $\underline{\mathbf{5}}$ in 2-propanol were allowed to sonicate for $1 \mathrm{~h}$ at $20^{\circ} \mathrm{C}$ in the presence of MNPs. After magnetic decantation, the supernatant containing pyrenes non-specifically bound to the surface was separated and the hybrid MNPs were washed 10 times. 
The hybrid MNPs were next analyzed by microanalysis and by comparison to the naked $\mathrm{Co} / \mathrm{C}$ MNPs, the loading could be determined. For both $\underline{\mathbf{3}}$ and $\underline{\mathbf{5}}$ ligands, a loading of $0.03 \mathrm{mmol}$ of pyrene tag per g of MNPs was found which is significantly lower than the one obtained in the case of phosphine ligands previously reported ( 0.1 and 0.15 for pyrene-tagged ligands bearing one or 5 phosphines respectively ${ }^{8 b}$ ). This lower loading may be rationalized by the absence of water known to favor attractive interactions between aromatic moieties and consequently stronger stacking behaviours. ${ }^{8 \mathrm{~d}}$

Next the catalytic activities of the Ru complexes involving $\underline{\mathbf{3}}$ or $\underline{\mathbf{5}}$ were evaluated in the transfer hydrogenation of nitrobenzene under the conditions previously reported by Beller and coll. (Figure 4). ${ }^{13 \mathrm{a}}$ Therefore, the Ru precursor $\left[\left\{\mathrm{RuCl}_{2}(\mathrm{p} \text {-cymene })\right\}_{2}\right]$ and the ligand were first heated at $60{ }^{\circ} \mathrm{C}$ for 30 minutes before MNPs were added and the mixture sonicated for 30 minutes at 20 ${ }^{\circ} \mathrm{C}$. Next $\mathrm{KOH}$ and nitrostyrene were introduced and the reaction allowed to reflux for $15 \mathrm{~h}$, time necessary to observe full conversion in the case of both ligands. After cooling down to room temperature, the crude was sonicated for 30 minutes at $20{ }^{\circ} \mathrm{C}$ and magnetic decantation was achieved with the magnet. The MNPs were rinced twice with 2-propanol and the joined solutions analyzed. Both Ru complexes involving $\underline{\mathbf{3}}$ and $\underline{\mathbf{5}}$ yielded the expected aniline selectively in quantitative yield as confirmed by ${ }^{1} \mathrm{H}$ NMR (using 1,3,5-trimethoxybenzene as the standard). To the dried MNPs, the nitrobenzene and 2-propanol were added to perform the $2^{\text {nd }}$ run and the same procedure was applied for each run. While a decrease of the activity was observed from the $6^{\text {th }}$ run in the case of terpyridine $\underline{\mathbf{3}}$ (formation of expected aniline and also of diazobenzene, Fig. 4 footnote), the catalytic system involving multivalent ligand $\underline{\mathbf{5}}$ could be reused 8 times with no loss of activity. In the latter case, the supported system thus enabled to improve at least by eight the turnover number of the parent molecular catalyst (at least 160 instead of 20). 
It is worthy to note that when the reaction was performed with $2,2^{\prime}: 6^{\prime}, 2^{\prime \prime}$-terpyridine instead of pyrene-tagged terpyridines $\underline{\mathbf{3}}$ or $\underline{\mathbf{5}}$, the catalytic system could not be recycled since the MNPs recovered by magnetic decantation displayed no catalytic activity. This suggested that the pyrene tag is required for the Ru-terpyridine complexes interact with the MNPs graphene surface. In the absence of $\mathrm{Ru}(\mathrm{II})$, a competitive interaction of terpyridines with the graphene surface can however not be excluded. Indeed, the extinction was observed after the addition of $2 \mathrm{mg}$ of MNPs in the case of ligand $\underline{\mathbf{5}}$ bearing 5 terpyridine moieties while $6 \mathrm{mg}$ were necessary in the case of ligand $\underline{\mathbf{3}}$ (for a same initial concentration of pyrene tags, Figure 2). This might suggest a non-innocent role of the terpyridine moieties. However, such terpyridine-graphene interactions are unlikely to occur when the terpyridine ligands are complexed to $\mathrm{Ru}(\mathrm{II})$ for both electronic and steric reasons, wellknown $\mathrm{Ru}(\mathrm{II})$-terpyridine complexes displaying an octahedral geometry. ${ }^{13 \mathrm{~b}}$ Indeed, the addition of MNPs on a solution of the Ru(II) complex prepared from dichloro( $p$-cymene)ruthenium(II) dimer) and 2,2':6',2"-terpyridine in 2-propanol did not induce any decrease of the absorption intensity by UV-vis spectroscopy. Accordingly, previous studies focused on the interactions between pyrenetagged terpyridine-metal complexes and graphene did not report the existence of terpyridinegraphene interaction. ${ }^{18 \mathrm{~b}}$ 

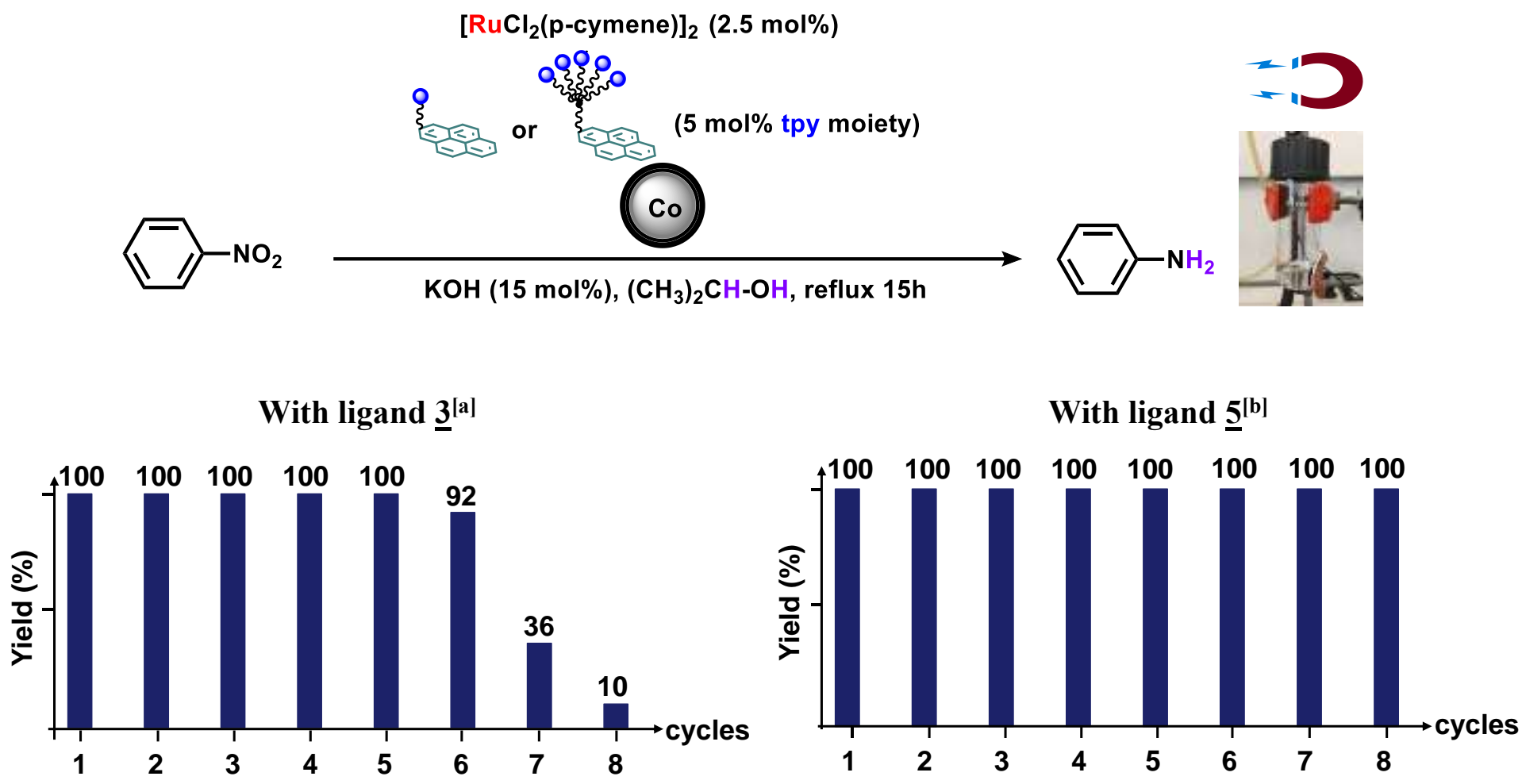

Figure 4: Catalytic performances of Ru catalysts for the transfer hydrogenation of nitrobenzene into aniline $[\mathrm{a}]\left[\mathrm{RuCl}_{2}(\mathrm{p} \text {-cymene })\right]_{2}(0.0125 \mathrm{mmol})$, pyrene-tagged $\underline{\mathbf{3}}(0.025 \mathrm{mmol}), \mathrm{MNPs}, \mathrm{KOH}(0.075 \mathrm{mmol})$, $\mathrm{PhNO}_{2}(0.5 \mathrm{mmol}), 2$-propanol $(10 \mathrm{~mL})$. For the $6^{\text {th }}$ run: $4 \%$ of azobenzene; for the $7^{\text {th }}$ run: $17 \%$ of azobenzene and $15 \%$ of azoxybenzene; for the $8^{\text {th }}$ run: $10 \%$ conversion of $\mathrm{PhNO}_{2}$. [b] $\left[\mathrm{RuCl}_{2}(\mathrm{p} \text {-cymene })\right]_{2}$ (0.0125 mmol), pyrene-tagged $\underline{\mathbf{5}}(0.005 \mathrm{mmol}), \mathrm{MNPs}, \mathrm{KOH}$ (0.075 mmol), $\mathrm{PhNO}_{2}$ (0.5 mmol), 2-propanol $(10 \mathrm{~mL})$. Yields were determined by ${ }^{1} \mathrm{H}$ NMR spectroscopy using 1,3,5-trimethoxybenzene as the standard. For recycling experiments: see general procedure in Experimental Section and SI p. 5.

The Ru amount present in the crude obtained after magnetic decantation was measured by ICPMS at each of the 6 first runs. In the case of both ligands, the most important Ru leaching was observed for the first two runs (see SI, Table S1, entries 1-2). From the $3^{\text {rd }}$ run, the amount of Ru leached was found to be low and stable (around 2-7 ppm in the case of $\underline{\mathbf{3}}$, less than 4 ppm in the case of $\underline{\mathbf{5}}$, see SI, Table S1). Noteworthy, the criteria for the final active pharmaceutical ingredients specify that the residual ruthenium has to be less than ten parts-per-million $\left(<10 \mathrm{ppm}^{21}\right)$. Therefore, the amines prepared met the requirements of the pharmaceutical industry from the third 
run whatever the ligand. The Ru leaching detectable on the first runs may correspond to $\mathrm{Ru}$ not specifically bound to the MNPs.

HRTEM, scanning transmission electron microscopy (STEM) and energy dispersive X-ray (EDX) spectra were recorded to get insight into the morphology of MNP functionalized by Ru complexes involving ligand $\underline{\mathbf{5}}$. Before catalysis (Figure 5a), whatever the size of MNPs (commercial MNPs used are widely polydisperse by nature ${ }^{5-8}$ ), the magnetic cores (dark areas) were found to be surrounded by amorphous grey shells containing the characteristic elements of the Ru- $\underline{5}$ complex $(\mathrm{P}, \mathrm{N}, \mathrm{Ru}, \mathrm{Cl}$, see SI Table S2b). Elemental mapping confirmed the main localization of atomic phosphorous, nitrogen and ruthenium around the cobalt magnetic cores (SI Table S3).

After 5 catalytic cycles, no obvious change in the morphology of MNPs could be noticed with cobalt cores still being surrounded by organic shells (Figure 5b). EDX spectra still highlighted the presence of $\mathrm{N}, \mathrm{P}$ and $\mathrm{Ru}$ while $\mathrm{Cl}$ could not be detected anymore which is consistent with the formation of the active $\mathrm{Ru}-\mathrm{H}$ complex from $\mathrm{KOH}$ and 2-propanol from the first run (SI Table S4). ${ }^{13 a}$

Noteworthy, an analogous morphology was found for hybrid MNPs obtained from $\underline{\mathbf{3}}$ before catalysis (SI, Table S2a). However, after 5 catalytic cycles (SI, Table S5), some agglomeration of MNPs could be highlighted which could contribute to explain the loss of activity observed from the $6^{\text {th }}$ cycle when using the monomeric ligand $\underline{\mathbf{3}}$ (Figure 4 ). 
a) Before catalysis

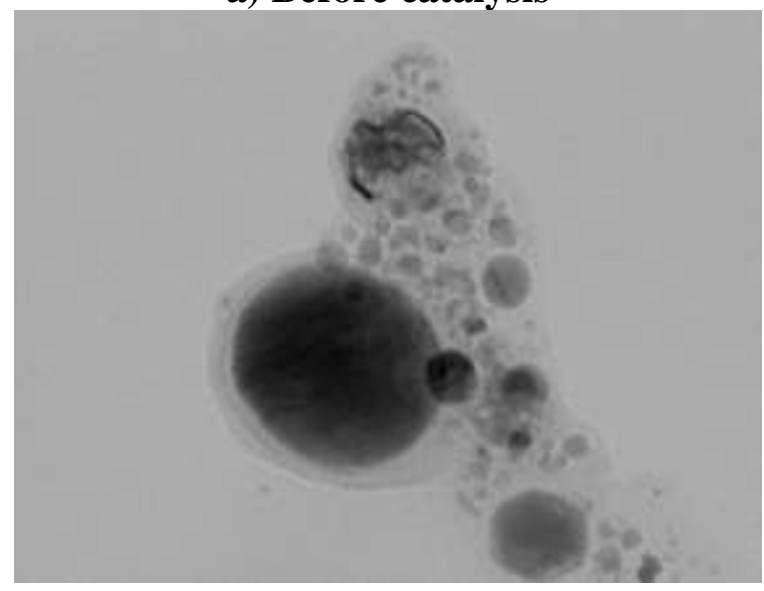

$50.0 \mathrm{~nm}$ b) After catalysis ( 5 cycles)

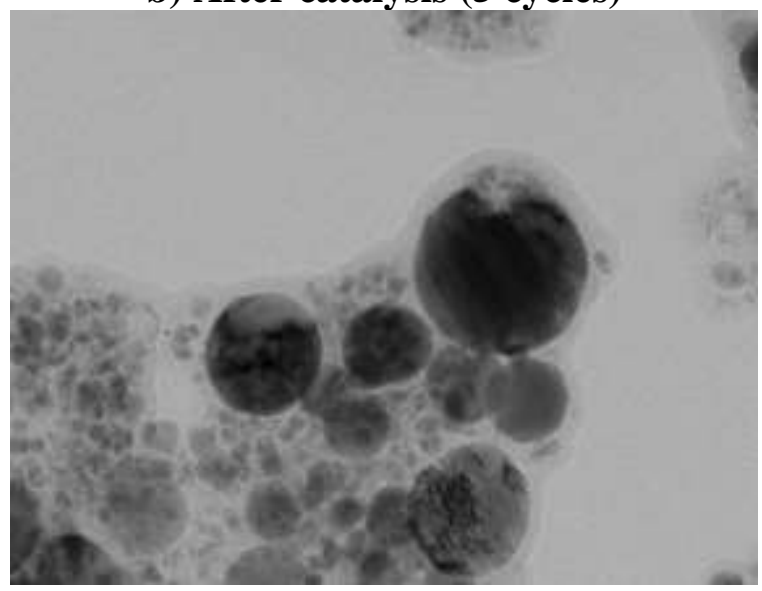

$50.0 \mathrm{~nm}$

Figure 5: Hybrid MNPs obtained from $\underline{\mathbf{5}}$ before catalysis (a) and after 5 cycles (b).

Finally, recycling experiments were achieved by changing the nitroarene at each run (Figure 6). As expected, the yields of anilines bearing different substituents (halide, electron-poor or electron donating) formed from 4-nitrotoluene, 4-chloronitrobenzene, 1-nitronaphtalene or 4methoxynitrobenzene were high and comparable to those obtained in the case of the parent molecular Ru-terpyridine complex (GC yields for each aniline: $92-96 \%{ }^{13 a}$ ). Noteworthy, the latter is one of the most active and selective homogeneous catalyst known to date for the transfer hydrogenation of nitroarenes using 2-propanol as a cheap, benign and easy-to-handle H-donor. To the best of our knowledge, related reported heterogeneous and homogeneous systems, in particular those based on 3d-non-noble metals, are mainly associated to hazardous hydrazine derivatives or expensive and waste-generating sodium borohydride. ${ }^{11 \mathrm{~b}}$ The reported methodology thus appears as complementary of existing ones. The anilines formed quantitatively can be easily isolated from the crude after a straightforward work-up including magnetic decantation, washings of the MNPs and evaporation of 2-propanol (see SI Figure S2). 


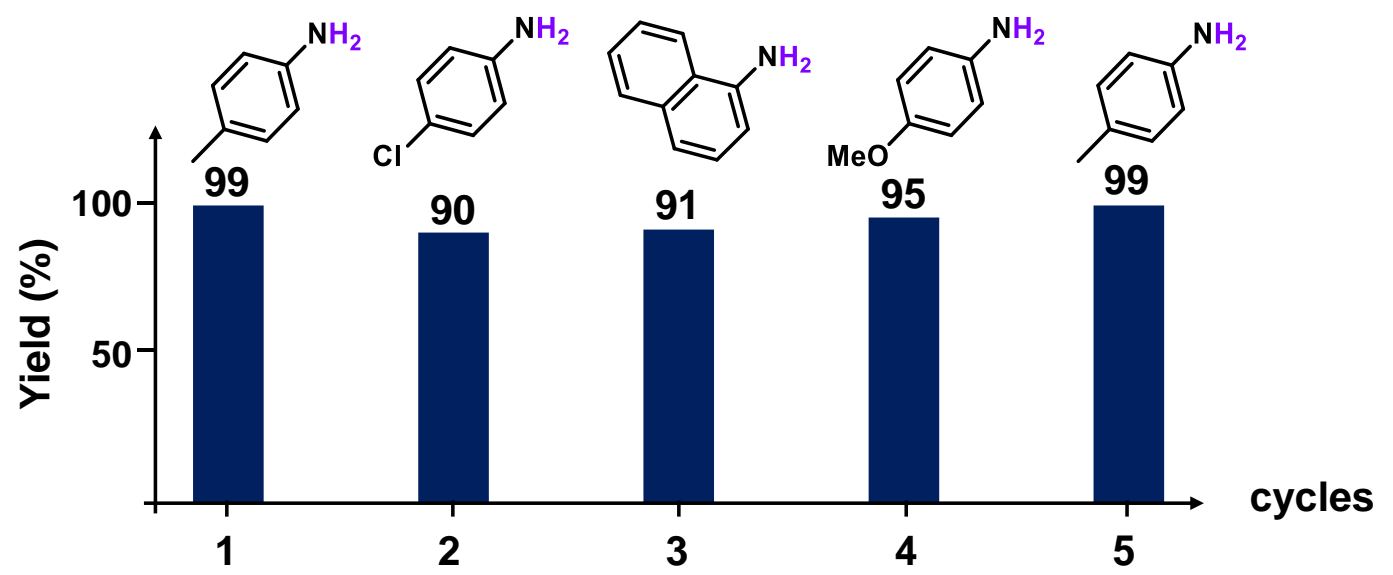

Figure 6: Recycling tests by changing the nitroarene at each run (case of ligand $\underline{5}$ ) ${ }^{\text {[a] }}$

[a] $\left[\mathrm{RuCl}_{2} \text { (p-cymene) }\right]_{2}(0.0125 \mathrm{mmol})$, pyrene-tagged $\mathbf{5}$ (0.005 mmol), MNPs, $\mathrm{KOH}(0.075 \mathrm{mmol}), \mathrm{ArNO}_{2}$ $(0.5 \mathrm{mmol}), 2$-propanol $(10 \mathrm{~mL})$ for the first run and general procedure for recycling experiments (see Experimental section and SI p. S5). [b] Yields were determined by ${ }^{1} \mathrm{H}$ NMR spectroscopy using 1,3,5trimethoxybenzene as the standard. For the fifth run, $p$-toluidine was directly isolated from the crude obtained after magnetic decantation of MNPs and evaporation of 2-propanol (90\% isolated yield, see SI, Figure S2).

\section{CONCLUSION}

To conclude, two $\mathrm{Ru}$ complexes involving pyrene-tagged terpyridine ligands (either monovalent $\underline{\mathbf{3}}$ or multivalent $\underline{\mathbf{5}}$ ) active in nitroarene transfer hydrogenation could be successfully supported on MNPs through $\pi$-stacking interactions. One main advantage of these systems is that the catalyst is free in refluxing 2-propanol where the H-transfer occurs thus allowing to reach the same activity than the parent molecular terpyridine-Ru catalyst. Besides, when back to roomtemperature, the interactions between the pyrene-tagged complexes and the MNPs are restored enabling the efficient recovery of the catalysts by simple magnetic decantation with a magnet. The catalyst involving the multivalent ligand $\underline{\mathbf{5}}$ can be reused at least 8 times and the anilines prepared meet the requirements of the pharmaceutical industry in terms of $\mathrm{Ru}$ contaminants $(<10 \mathrm{ppm})$ from the third run. This system is compatible with an organic environmentally-friendly solvent, do not require chromatographic purification and displays a high activity upon recycling which corresponds to the main challenges that catch-and-release catalysts have generally still to face. ${ }^{9 a}$ 
Besides, the occurrence of interactions between the pyrene-tagged catalyst and the surface of the MNPs are supported by a network of facts including (i) the fluorescence studies bringing qualitative information, (ii) the quantitative microanalyses achieved on hybrid MNPs involving ligands $\underline{\mathbf{3}}$ or $\underline{\mathbf{5}}$ after several washings, (iii) the HRTEM images showing an homogeneous repartition of the organic ligands around the MNPs, (iv) the fact that the complex formed by same Ru precursor with 2,2':6',2'-terpyridine (without pyrene tag) could not be recovered with a magnet. In addition, the existence of reversible interactions between the pyrene tag and the surface of $\mathrm{Co} / \mathrm{C}$ MNPs was assessed for the first time in non-aqueous medium which opens new prospects for the use of these MNPs as supports in various organic reactions. In addition, terpyridines being very widely used ligands, ${ }^{22}$ the systems reported here may find applications in many other catalytic reactions or even in other areas. Along these lines, further studies are currently underway in our laboratories.

\section{ASSOCIATED CONTENT}

Supporting Information: Procedures to prepare the ligands $\underline{\mathbf{2}}, \underline{\mathbf{3}}$ and $\underline{\mathbf{5}}$ and their characterization (NMR and mass spectra); grafting measurements and details about catalytic reactions and determination of Ru amounts present in the crude after each run by ICP-MS ; HRTEM images and related EDX spectra. The Supporting Information is available free of charge on the ACS Publications website.

\section{AUTHOR INFORMATION}

\section{Corresponding Author}

Armelle Ouali. Institut Charles Gerhardt Montpellier ICGM, Univ. Montpellier, CNRS, ENSCM, Montpellier 34090, France; orcid.org/0000-0001-7436-776X. Email: armelle.ouali@enscm.fr.

\section{Authors}

Houria Asri. Institut Charles Gerhardt Montpellier ICGM, Univ. Montpellier, CNRS, ENSCM, Montpellier 34090, France.

Olivier Dautel. Institut Charles Gerhardt Montpellier ICGM, Univ. Montpellier, CNRS, ENSCM, Montpellier 34090, France. orcid.org/0000-0003-2327-5376.

\section{Author Contributions}


The manuscript was written through contributions of all authors and all authors have given approval to the final version of the manuscript. H.A. and A.O. participated in the preparation of ligands and catalysis experiments and D.O. carried out the fluorescence spectroscopic studies. A.O. designed the investigations and coordinated the project.

\section{Notes}

The authors declare no competing financial interest.

\section{ACKNOWLEDGMENT}

The authors gratefully thank CNRS for funding, Labex CheMISyst - ANR-10-LABX-05-01 for HA grant and Erwan Oliveiro, director of the Microscopy Platform, University of Montpellier.

\section{REFERENCES}

(1) Pagliaro, M. ; Sels, B. F. Supported Molecular Catalysts. ChemCatChem 2018, 10, 1663-1665 (and articles of this special issue).

(2) Hübner, S. ; de Vries, J. G. ; Farina, V. Why Does Industry Not Use Immobilized Transition Metal Complexes as Catalysts ? Adv. Synth. Catal. 2016, 358, 3-25.

(3) Keller, M.; Hameau, A.; Spataro, G.; Ladeira, S.; Caminade, A.-M.; Majoral, J.-P.; Ouali, A. An efficient and recyclable dendritic catalyst able to dramatically reduce palladium leaching in Suzuki couplings. Green Chem., 2012, 14, 2807-2815.

(4) (a) Gun'ko, Y. K.; Govan, J. Recent Advances in the Application of Magnetic Nanoparticles as a support for Homogeneous Catalysts. Nanomaterials 2014, 4, 222-241; (b) Huang, Y.; Zhang, W. Magnetic Nanoparticle-Supported Organocatalysis. Green Process Synth. 2013, 2, 603-609; (c) Polshettiwar, V., Luque, R. ; Fihri, A. ; Zhu, H. ; Bouhrara, P. Basset, J.-M. Magnetically Recoverable Nanocatalysts. Chem. Rev. 2011, 111, 3036- 3075 ; (d) Kainz, Q.M.; Reiser, O. Polymer- and Dendrimer-coated magnetic nanoparticles as versatile supports for catalysts, scavengers, and reagents. Acc. Chem. Res. 2014, 47, 667-677.

(5) Grass, R. N.; Athanassiou, E. K.; Stark, W. J. Covalently functionalized cobalt nanoparticles as a platform for magnetic separations in organic synthesis. Angew. Chem. Int. Ed. 2007, 46, 4909.

(6) Supplied by Merck.

(7) Schaetz, A.; Long, T.R.; Grass, R.N.; Stark, W.J.; Hanson, P.R.; Reiser, O. Immobilization on a nanomagnetic $\mathrm{Co} / \mathrm{C}$ surface using rom polymerization: Generation of a hybrid material as support for a recyclable palladium catalyst. Adv. Funct. Mater. 2010, 20, 4323-4328.

(8) (a) Wittmann, S.; Schaetz, A.; Grass, R.N.; Stark, W.J.; Reiser, O. A recyclable nanoparticlesupported palladium catalyst for the hydroxycarbonylation of aryl halides in water. Angew. Chem. Int. Ed. 2010, 49, 1867-1870 ; (b) Keller, M; Collière, V.; Reiser, O.; Caminade, A.-M.; Majoral, J.-P.; Ouali, A. Pyrene-Tagged Dendritic Catalysts Noncovalently Grafted onto Magnetic Co/C Nanoparticles: An Efficient and Recyclable System for Drug Synthesis. Angew. Chem. Int. Ed. 2013, 52, 3626-3629; (c) Folgado, E., Guerre, M.; Mimouni, N.; Collière, V.; Bijani, C.; Moineau-Chane Ching, K.; Caminade, A.-M.; Ladmiral, V.; Améduri, B.; Ouali, A. $\pi$-Stacking Interactions of Graphene-Coated Cobalt Magnetic Nanoparticles with PyreneTagged Dendritic Poly(Vinylidene Fluoride). ChemPlusChem 2019, 84, 78-84.

(9) (a) Gruttadauria, M.; Giacalone, F.; Noto, R. "Release and Catch" catalytic systems. Green Chem. 2013, 15, 2608-2618; (b) Paul, I.; Mittal, N.; De, S.; Bolte, M.; Schmittel, M. J. Am. Chem. Soc. 2019, 141, 5139-5143; (c) Qi, Miao; Chew, B. K. J.; Yee, K. G.; Zhang, Z.-X.; 
Young, D. J.; Hor, T. S. A. RSC $A d v$. 2016, 6, 23686-23692; (d) Shi, X.-L.; Lin, H.; Li, P.; Zhang, W. ChemCatChem 2014, 6, 2947-2953; (e) Pavia, C.; Giacalone, F.; Bivona, L. A.; Salvo, A. M. P.; Petrucci, C.; Strappaveccia, G.; Vaccaro, L.; Aprile, C.; Gruttadauria, M. J. Mol. Cat. A 2014, 387, 57-62; (f) Pflueger, I.; Benito, J. M. Org. Lett. 2013, 15, 2354-2357.

(10) Barath, E. Hydrogen Transfer Reactions of Carbonyls, Alkynes and Alkenes with Noble Metals in the Presence of Alcohols/Ethers and Amines as Hydrogen Donors. Catalysts 2018, 8, 671-686.

(11) (a) Song, J.; Huang, Z.-F.; Pan, L.; Li, K.; Zhang, X.; Wang, L.; Zou, J.-J. Review on selective hydrogenation of nitroarene by catalytic, photocatalytic and electrocatalytic reactions. Appl. Catal. B: 2018, 227, 386-408; (b) Formenti, D.; Ferretti, F.; Scharnagl, F. K.; Beller, M. Reduction of nitro Compounds Using 3d-Non-Noble Metal Catalysts. Chem. Rev. 2019, 119, 2611-2680; (c) Shaikh, N. S. Sustainable Amine Synthesis: Iron Catalyzed Reactions of Hydrosilanes with Imines, Amides, Nitroarenes and Nitriles. Chemistryselect 2019, 4, 67536777.

(12) Jia, W.-G.; Ling, S.; Zhang, H.-N.; Sheng, E.-H.; Lee, R. Half-Sandwich Ruthenium Phenolate-Oxaline Complexes: Experimental and Theoretical Studies in Catalytic Transfer Hydrogenation of Nitroarenes. Organometallics 2018, 37, 40-47.

(13) (a) Jadadeesh, R. V.; Wienhöfer, G.; Westerhaus, F. A.; Surkus, A.-E.; Junge, K.; Beller, M. A convenient and General Ruthenium-Catalyzed Transfer Hydrogenation of Nitro- and Azobenzenes. Chem. Eur. J. 2011, 17, 14375-14379; (b) R. Ziessel, V. Grosshenny, M. Hissler, C. Stroh. cis-[Ru(2,2':6,2''-terpyridine)(DMSO)Cl 2$]$ : Useful Precursor for the Synthesis of Heteroleptic Terpyridine Complexes under Mild Conditions. Inorg. Chem. 2004, 43, 42624271.

(14) (a) Gulyani, A.; Dey, N.; Bhattacharya, S. A. Highly Responsive Fluorescent Assemblies Allow for Unique, Multiparametric Sensing of the Phospholipid Membrane Environment. Chem. Eur. J. 2019, 25, 1507-1514; (b) Qin, Q.-P.; Meng, T.; Tan, M.-X.; Liu, Y.-C.; Wang, S.-L.; Zou, B.-Q.; Liang, H. Synthesis, Characterization and Biological Evaluation of Six Highly Cytotoxic Ruthenium(II) Complexes with 4'-Substituted-2,2':6',2'-Terpyridine. Med. Chem. Commun. 2018, 9, 525-533; (c) Gulyani, A.; Dey, N.; Bhattacharya, S. A Unique SelfAssembly-Driven Probe for Sensing a Lipid Bilayer; Ratiometric Probing of Vesicle to Micelle Transition. Chem. Commun. 2018, 54, 5122-5125; (d) Peng, X.; Xu, Y.; Sun, S.; Wu, Y.; Fan, J. A Ratiometric Fluorescent Sensor for Phosphates: Zn2+-Enhanced ICT and Ligand Competition. Org. Biomol. Chem. 2007, 5, 226-228.

(15) (a) Mandal, A.; Maity, A.; Bag, S.; Bhattacharya, S. A; Das, A. K.; Basak, A. Design and Synthesis of Dual Probes for Detection of Metal Ions by LALDI MS and Fluorescence: Application in Zn(II) Imanging in Cells. RSC Adv. 2017, 7, 7163-7169; (b) Karmakar, S.; Maity, D.; Mardanya, S.; Baitalik, S. Demonstration of Multiple Logic Operations in a Heteroleptic Pyrene-Phenylimidazole-Terpyridine Conjugate Based on Optical Responses by Selective Anions and Cations: An Experimental and Theoretical Investigation. J. Phys. Chem. A. 2014, 118, 9397-9410; (c) Cox, N. M.; Harding, L. P.; Jones, J. E.; Pope, S. J. A.; Rice, C. R.; Adams, H. Probing Solution Behaviour of Metallosupramolecular Complexes Using Pyrene Fluorescence. Dalton Trans. 2012, 41, 1568-1573; (d) Maity, D.; Bhaumik, C.; Mondal, D.; Baitalik, S. Ru(II) and Os(II) Complexes Based on Terpyridyl-Imidazole Ligand Rigidly Linked to Pyrene: Synthesis, Structure, Photophysics, Electrochemistry, and Anion-Sensing Studies. Inorg. Chem. 2013, 52, 13941-13955; (e) Lin, H.-C.; Straus, D. A.; Johnson, V. A.; Lu, J. E.; Lopez, L.; Terrill, R. H. Preparation and Electrochemistry of a Pyrene-Linked Iron 
Terpyridine Anodic Redox Polymer. Electrochimica Acta. 2012, 62, 140-146; (f) McQueen, E. W.; Goldsmith, J. I. Electrochemical Analysis of Single-Walled Carbon Nanotubes Functionalized with Pyrene-Pendant Transition Metal Complexes. J. Am. Chem. Soc. 2009, 131, 17554-17556.

(16) (a) Zych, D.; Slodek, A.; Golba, S.; Krompiec, S. Cyclometalated Ruthenium, Osmium, and Iridium Complexes Bridged by an NCN-Pyrene-NCN Derivative - Synthesis and Comparison of Optical, Thermal, and Electrochemical Properties. Eur. J. Inorg. Chem. 2018, 1581-1588. (b) Zych, D.; Slodek, A.; Golba, S.; Pajak, M.; Krompiec, S; Spolnik, G.; Danikiewicz, W. Mono- and Diruthenium, Symmetrical and Unsymmetrical Complexes Bridged by Pyrene Derivatives: Experimental and Theoretical Studies. Eur. J. Inorg. Chem. 2017, 3868-3877. (c) Yao, C.-J.; Nie, H.-J.; Yang, W.-W.; Yao, J.; Zhong, Y.-W. Combined Experimental and Computational Study of Pyren-2,7-diyl Bridged Diruthenium Complexes with Various Terminal Ligands. Inorg. Chem. 2014, 54, 4688-4698.

(17) Ao, L.; Gao, Z.; Wang, F.; Song, F. Supramolecular Amphiphile Derived From non-Covalent Alkynylplatinum(II) Terpyridine Molecular Tweezer/Pyrene Complexation. Tetrahedron Lett. 2016, 57, 4549-4555.

(18) (a) Rodriguez-Lopez, J.; Ritzert, N. L.; Mann, J. A.; Tan, .; Dichtel, W. R.; Abruna, H. D. Quantification of the Surface Diffusion of Tripodal Binding Motifs on Graphene Using Scanning Electrochemical Microscopy. J. Am. Chem. Soc. 2012, 134, 6224-6236; (b) Mann, J. A.; Rodriguez-Lopez, J.; Abruna, H. D.; Dichtel, W. R. Multivalent Binding Motifs for the Noncovalent Functionalization of Graphene. J. Am. Chem. Soc. 2011, 133, 17614-17617.

(19) (a) Jiang, H.; Wu, P.; Zhang, Y.; Jiao, Z.; Xu, W.; Zhang, X.; Fu, Y.; He, Q.; Cao, H.; Cheng, J. Hyperbranched Polymer Based Fluorescent Porbes for ppt Lever Nerve Agent Simulant Vapor Detection. Anal. Methods 2017, 9, 1748-1754; (b) Fermi, A.; Ceroni, P.; Roy, M.; Gingras, M., Bergamini, G. Synthesis, Characterization, and Metal Ion Coordination of a Multichromophoric Highly Luminescent Polysulfurated Pyrene. Chem. Eur. J. 2014, 20, 10661-10668; (c) Karmakar, S.; Maity, D.; Mardanya, S.; Baitalik, S. Multiphotochromic Bimetallic Ru(II) Terpyridine Complexes Based on Pyrenyl-bis-Phenylimidazole-Terpyridine Spacer: Synthesis, Photophysics, Spectroelectrochemistry, and TD-DFT Calculations. Inorg. Chem. 2014, 53, 12036-12049.

(20) Z. Guo, H. Yin, Y. Feng, S. He. Functionalization of single-walled carbon nanotubes with thermo-responsive poly(N-isopropylacrylamide): effect of the polymer architecture. $R S C A d v$. 2016, 6, 37953-37964.

(21) Permitted concentration limit of ruthenium impurity in drug products with daily doses of not more than 10 grams per day: 10 ppm. Abernathy, D. R. ; DeStefano, A. J. ; Cecil, T. L. ; Zaidi, K. ; Williams, R. L. and the USP Metal Impurities Advisory Panel. Metal Impurities in Food and Drugs. Pharmaceutical Research 2010, 27, 750-755.

(22) Wei, C.; He, Y.; Shi, X.; Song, Z. Terpyridine-metal complexes: Applications in catalysis and supramolecular chemistry. Coord. Chem. Rev. 2019, 385, 1-19. 